\title{
Using Podcasts as Audio Learning Objects
}

\author{
Zeynel Cebeci and Mehmet Tekdal \\ Çukurova University in Adana, Turkey
}

zcebeci@cukurova.edu.tr mtekdal@cukurova.edu.tr

\begin{abstract}
Podcasting is an audio content syndication through RSS feeds in the audioblogs. As a new application of audioblogging, podcasting uses the enclosures in RSS feeds for syndication and distribution of audio content to mobile music players on the Web. Despite the advantages of podcasting, there is a need for research that focus on the use of podcasts as learning objects. Incorporating podcasts into e-learning systems require some design and translation work to achieve the pedagogical needs. This paper presents an introductory investigation on approaches to tailor and use audio podcasts as learning objects in learning management systems and learning object repositories.
\end{abstract}

Keywords: podcasting, learning objects, audioblogging, e-learning, mobile learning, instructional design

\section{Introduction}

As is the case in other disciplines, innovations in information and communication technologies (ICT) have created incremental and radical transformations in the area of education, especially in the past decade. E-learning, equipped with ICT-enhanced learning, is continuing to move educational activities beyond the classroom. Currently, podcasting is being debated as a new promising e-learning tool that will possibly change mobile learning. Podcasting or audiocasting is a simple realization of audio content syndication that mainly targets mobile digital devices via audioblogs on the Web. In Wikipedia, podcasting is defined as online publishing of files in a way that allows for the subscription-like syndication and distribution of files as they become available. Most podcasts are audio in MP3 format, syndicated through the RSS protocol (Wikipedia, 2005). Meng $(2005$, p. 1) defines podcasting as "the process of capturing an audio event, song, speech, or mix of sounds and then posting that digital sound object to a Web site or "blog" in a data structure called an RSS 2.0 envelope (or feed)". According to these definitions, podcasting can be characterized with two main features:

1. Podcasting is an audio content delivery approach based on Web syndication protocols such as RSS and/or Atom.

Material published as part of this journal, either on-line or in print, is copyrighted by the publisher of the Interdisciplinary Journal of Knowledge and Learning Objects. Permission to make digital or paper copy of part or all of these works for personal or classroom use is granted without fee provided that the copies are not made or distributed for profit or commercial advantage AND that copies 1) bear this notice in full and 2) give the full citation on the first page. It is permissible to abstract these works so long as credit is given. To copy in all other cases or to republish or to post on a server or to redistribute to lists requires specific permission and payment of a fee. Contact Publisher@ijklo.org to request redistribution permission.
2. Podcasting aims to distribute content to be used with mobile and digital audio/video players such as iPods including all other MP3 players, cell phones and PDAs.

Hence we can formulate podcasting as following: 
Podcasting $=$ Web syndication $(R S S$, Atom) + Audio content (talk shows, music, news, and certainly learning resources...) + Mobile devices (mp3 players, PDAs, cell phones...)

Here, Web syndication is a way of publishing informational feeds about the new and updated content of a Web site to other Web sites or people who subscribed to these feeds. A feed or a channel is a type of XML file that contains information about new or updated content of a Website or a blog. Although Atom is an emerging protocol, various versions of RSS are primarily being used in building syndications of feeds. RSS feeds (XML files written according to RSS specifications) are created by content publishers/developers and then delivered to their subscribers through reading by a feed reader or feed aggregator. Feed readers are the programs that regularly or periodically check the new information on subscribed feeds and then automatically download the referenced content files to a user's local device. Long (2003, p. 2) explained that "RSS is primarily used to distribute news and other Web content, and it was originally developed at Netscape to feed news headlines and related information to their portal pages. These so-called channels have become the primary mechanism by which automatic distribution of news and other event-oriented information bits are enabled, a process known as providing syndication services".

Currently, the distributed content through the RSS feeds is primarily composed of text-based news headlines, however; the content can also be published in any electronic file formats, such as plain texts, formatted documents, presentations, audios, videos, and animations. Adam Curry's idea about distribution of audio with RSS syndication came into existence with RSS 2.0 specification. He proposed that any kind of media could be referenced with an "enclosure" tag of RSS. Applying this idea, his audioblogging was published by Radio Userland. In this kind of syndication large objects wrapped up in RSS enclosures can be set to download at night, when traffic is lighter. In the morning, the user can have access to large media on their own computer (c.f. Lomas, 2003).

RSS 2.0, published in July 2003, is the successor of RSS 0.92. It is the latest version of RSS specifications. Its "enclosure" element, indicating an audio file in a feed, has been widely used to download MP3 files to digital audio players automatically. Dave Winer, one of the co-authors of RSS 2.0, has experimented on audio enclosures of RSS 2.0 with a reader called iPodder on iPods. This kind of syndication is called (mistakenly) "podcasting" because it is related to Apple's iPods. Additionally, during 2004 Apple's iPod was the most popular DAP because of its highcapacity hard disk compared to other devices with flash disks. The technological superiority of iPods is further reinforced with the usage of the term "podcasting" for defining audio syndication. A more suitable term, however; could be audiocasting because audio syndication and distribution via RSS can be applied to all kind of mobile audio players today. It is likely that in the future the term "podcasting" may be replaced with "audiocasting" as a more descriptive term of audio syndication and distribution.

Podcasting is not a new technology but rather a new innovative method of Web-based broadcasting that may be used for automatically transferring digital audio content to mobile devices. It is an XML-based syndication meant to disseminate audio content in the Web that has become well known in the last two years. The popularity of audio content syndication makes mobile learning applicable for a large number of students. Similarly, Downes (2004, par. 15) points that "an emerging trend, called 'mobile learning', foresees the delivery of learning content through mobile devices such as personal telephones, PDAs and similar tools". He also emphasizes that "the impact of wireless learning is that, because content is available anywhere, learning is no longer tied to a particular location. As XML encoded content and syndicated content delivery become entrenched, there will be little, if any, limitation on the place or manner in which learning may be available." 
The basic advantage of podcasting in education is the portability and convenience of listening to learning resources anytime and anywhere without requiring extensive technical knowledge. Podcasts can be automatically downloaded to almost all kinds of mobile devices, such as MP3 players, cellular phones, PDAs, and mobile computers. Learning materials downloaded into mobile devices can be listened to by learners in their own time and place. But in spite of this technological advantage of podcasting, there are some issues to consider before using podcasts in learning object based instruction.

First of all, if podcasts are described with learning object metadata they should be reusable, accessible, and searchable audio learning objects via learning object repositories (LOR). In addition to reusability, podcasts should also be designed to match pedagogic needs to support learning. Therefore, podcasts should have learning objectives associated with them. Secondly, design of podcasts as learning objects should enable its effective inclusion in learning content management system (LCMS) in order to assemble the lessons or courses for various purposes. This will also provide personalization to meet the individual learning style of each learner.

This paper primarily aims to introduce the potential advantages of podcasting for education. Additionally, some principles on transformation of podcasts to learning objects and producing audio learning objects for e-learning through podcasting are examined. Finally interactions between the systems such as LOR, LMS/LCMS and audioblogs are evaluated.

\section{Podcasting and Education}

Podcasting or audio content syndication can be considered as a complimentary tool to e-learning due to some of its inherited pedagogic advantages. Therefore, podcasting should be taken into account as a means to utilize and evaluate the growing prevalence of mobile players in e-learning.

Firstly, podcasting serves anytime and anywhere mobile learning. After podcasts are downloaded into any mobile player, they can be listened to at one's convenience. The flexibility of merely listening is a technological advantage of podcasting that may make mobile learning applicable, cheaper, and popular when it is compared to its counterparts such as WAP-based or Web-based mobile learning.

Podcasting has an instant-application potential for education since millions of young people have already bought mobile music players (mostly MP3 players). In the near future, it is highly probable that the availability of cheaper but advanced technology player devices and applications in mobile market might lead to an increased use of mobile players.

Perhaps, one of the most important pedagogic characteristics offered by podcasting is learning through listening. For many people, listening may be more attractive and less tedious than reading. It is well known that human beings have used listening as a primary method for thousand of years in learning process. Listening may motivate students who do not like reading.

Podcasting makes possible content that is attractive to students. In order to attract students, course content could be mixed with short length fragments of popular songs as insertions or speech backgrounds.

Podcasting may also be a useful tool in e-learning environments for the visually challenged. Beyond being an independent way of delivering course content in any audio format, podcasting may also be integrated with Web-based e-learning models. Audio recording and podcasting of live lectures given in the classes of arts and humanities may be quickly and practically used by educational institutions. Recording live conversations in lectures is not an expensive and difficult task since it may simply be done with the use of devices such as portable speech recorders or even MP3 players equipped with recording functionality. Podcasts can also be recorded with analog 
devices, but in this case a conversion process is required to convert analog records to digital audio formats before publishing.

Podcasting can also be treated as complementary tool of music, language and theatre education. Universities and other educational institutions can organize the collecting and publishing of audio in a central learning system and/or a podcasting repository. The audio may be published in teachers' personal Weblogs on the Internet (Norman, 2004). When RSS feeds are published in personal Weblogs or institutional podcasting repositories, they can be easily retrieved by students who are subscribed to these feeds. Educational institutions may achieve that objective by installing RSS server software as a part of their existing Web sites or learning management systems to edit and publish podcasts to students.

Podcasting eases accession and selection to a wide range of audio resources in the Web. This provides better cognitive-based personalization in learning. Martinez (2002, par. 12) explained that "cognitive-based personalization uses information about learning preferences or styles from a primarily cognitive perspective to deliver content specifically targeted to differing learner attributes. As an example, learners may choose to use an audio option because they prefer hearing text rather than reading it. Or, a learner may prefer the presentation of content in a linear fashion, rather than a random presentation."

\section{Converting Podcasts to Learning Objects: "Wafers-Like Audio Learning Objects"}

Currently most podcasts are just audio files recorded and distributed as MP3 files for noneducational purposes. Although many audio objects have been created and used for education over the years, they are often ordinary speech files that are recorded linearly in one of audio file formats such as MP3, WAV, RAM, etc. Perhaps these speech-only audios and podcasts are not considered as valuable learning objects because they do not have educational values.

When podcasts are created, they must adhere to learning object's functionalities such as reusability, interoperability, etc. Harman and Koohang (2004) concluded that a learning object can have educational value only when it is designed in such way that can be contextualized by the learner.

As stated by Wiley (2000a) the discussion of learning object characteristics, such as sequence, scope, and structure, leads one to consider what different types of learning objects might exist. Building and publishing a podcast with learning object characteristics is more important than seeing every podcast as a potential learning resource.

Producing podcasts for learning should be a personalization process that is made at the learning object level. Wafers-Like Audio Learning Object (WALO) can be applied to build the attractive forms of audio objects. A WALO may be considered as an audio object that consists of any number of fragments of speech, music, and voice effects. When compared to ordinary audio objects or podcast files, WALOs will clearly be more efficient in improving learning processes. For instance, keeping learner attention, regulating physiological capacity, retention abilities, and sensory channels of the students should be taken into account.

Sequence, topical density, and individual length of each fragment to be included in a WALO are key factors related to educational and technological requirements and/or limitations. Firstly, the duration or length of WALO fragments is one of the key points that should be considered in the design of a WALO because the size of an audio file is much bigger than its text equivalents. Long objects may cause some technological and psychological issues. For example, the Internet bandwidth is a technological factor that limits the size of a WALO. Whereas downloading long objects may not be a significant problem with high bandwidth connections. It's generally a serious problem in low bandwidth like dialup connections to the Internet. 
Secondly, acceptable time for listenability of a WALO also depends on some psychological limits of learners because long objects generally results in loss of attention in listening and a subsequent decrease in comprehension. Sustaining audiences' attention on the content for a long time is normally difficult. The preliminary findings from an unpublished survey study to determine the students' opinions on the role of MP3 players in education showed that an object should not be longer than 15 minutes (Berk \& Cebeci, 2005). Students find that long media will cause a remarkable loss of attention in listening. Moreover high sized podcasts will be completely unsuitable with music players having low capacity flash memories. On the other hand, long podcasts will be advantageous in serving the content as whole or single resource.

Sequencing the fragments in a logical order is another important point in design of a WALO. Prior to sequencing, a long recorded speech should be sliced into smaller independent units of topics. Then they should be remixed or combined with music and appropriate fragments in order to increase listenability of the audio object. Listening to this kind of mixed content may be far more engaging than listening to a long speech-only audio or reading a long text-based equivalent material. This mixed content may provide a more attractive and motivated learning environment.

A highly quality audio learning material possesses qualified sound processing techniques that consist of initial recording, fine tuning, clipping, inserting, and recombining. These are achieved in a well-equipped studio environment that normally requires high degree of knowledge, experience, and developmental costs.

Alternatively, "enriched audio content (EAC)" approach can be applied in order to reduce the costs originating from qualified processes and license fees. EAC encompasses the content related conversations emphasizing the important points in the content. Manning $(2005$, p. 2$)$ reports that "what one hears through the speaker's intonation, diction and inflection conveys a richer understanding not only of the content, but of the speaker. Listeners connect to that voice and may feel less isolated".

Finally, the topical depth or complexity of each fragment of a WALO should be taken into account to sustain learners' attention. The speech fragments located at the beginning of a WALO should be kept longer in duration but less dense in content. Denser speech fragments and longer non-content fragments should be placed at the end of the object. Normally a learner's attention is higher in the beginning of a lecture causing his/her increased understanding. Hence gradually increasing the content complexity from top to bottom by placing the high density context at the end of a WALO could be a more effective method. Similar advice has also been reported in some research studies. For example, Wiley $(2000 \mathrm{~b})$ recommends that learning objects should be presented in order of increased complexity, beginning with the simplest case.

As concluded above, the length and structure of an independent WALO depends on several psychological, physiological, and technological factors. The Internet infrastructure and dominant audio player technology in the market are some of the technological factors that merit attention. Learner attention, physiological capacity, retention ability and sensory channels are some examples of psychological and physiological factors. Therefore, determining the appropriate size and structure of a WALO is not an easy process and requires future research. For example, an evaluation of successful or popular radio talk shows may offer a good starting point on this context. Factors contributing to the success behind these kinds of programs may be used in order to provide guidance for developing mixed audio content or producing WALOs that make the content desirable to listen by students. Lastly, Keller's ARCS (attention, relevance, confidence and satisfaction) model (Keller, 1999) can be applied to WALO for gaining students' interest and attention during listening. 


\section{Inclusion of Podcasting into E-Learning}

Podcasts do not automatically become learning objects. If a learning object is simply published by RSS syndications, it becomes a podcast but a podcast becomes a learning object if it includes a learning objective and has educational values. Similarly Downes (2002, par 48) finds that "RSS is a powerful tool for content syndication, however, it lacks some important features needed to develop into a robust solution for the location and organization of educational content". Ip, Morrison, Currie, and Mason (2000) introduced their model on managing non-educationally-focused online resources emphasizing pedagogical frameworks such as "resource based learning", "scaffold learning," and resources to achieve desired educational goals. The researchers believe that the majority of online resources, however; are not created as educational tools or classroom materials. A podcast without a learning goal will not be useful to support learning globally. Therefore, some modifications should be made on podcasts in order to transform and publish them as learning objects. The learning systems such as LORs and LMS/LCMSs must have some translation components in their architecture in order to manage podcasting as a learning tool.

As illustrated in Figure 1, when podcast feeds created via blogware in a weblog, they are syndicated into a Learning Object Repository (LOR). They will then be available to be read by subscribers of the LOR. Regular audioblog (or other weblog) feeds can also point an audio learning object which exists in a LOR. Similarly if a podcasting subsystem (blogware) is integrated into a LOR or LMS/LCMS, syndication will be possible to announce new audio objects that have been added into the LOR. Podcasting will make communication very easy between the parties such as administration, educators and learners of any LMS/LCMS. In addition, to ease the communication between the parties, audio syndication can also be used as a mean of automatic delivery of audio courses to the learners of a learning system. Levine, Lamb, and Norman (2003, par. 4) described and demonstrated that "RSS feeding approach can be easily applied to collections of learning objects as a vehicle for expanding the practice of discovery beyond the blast of a Web search. According to the authors, any repository that houses its content or meta-data in a database can, in a matter of hours, generate properly formed RSS feeds for describing."

The metadata used in podcasting is built with RSS that includes a very simple syndication protocol. Because RSS was specifically designed to simplify audio content syndication rather than fully describing an audio object, the RSS metadata of an audio object must be extended to transform podcasts to learning objects. The Learning Object Metadata (LOM) is the draft standard to describe the learning objects for reusability and interoperability. Hence, when an audio object is recorded into a LOR it should be meta-tagged for both LOM and RSS. LOM of an audio object is generally stored in a separate learning object metadata repository (LOMR) system or LOR itself. But, since there is no subsystem for storing RSS feeds in such systems, a special subsystem to deposit and manage the RSS feeds as feed objects should be taken into consideration in LOR and LMS/LCMS architecture. The feeds published, however; are stored in specialized feed folders in a regular audioblog. The RSS-LOM Module developed by Downes (2003) is an early translation from IEEE-LOM to RSS 1.0 to allow learning object repositories to syndicate listings and descriptions of learning objects. 


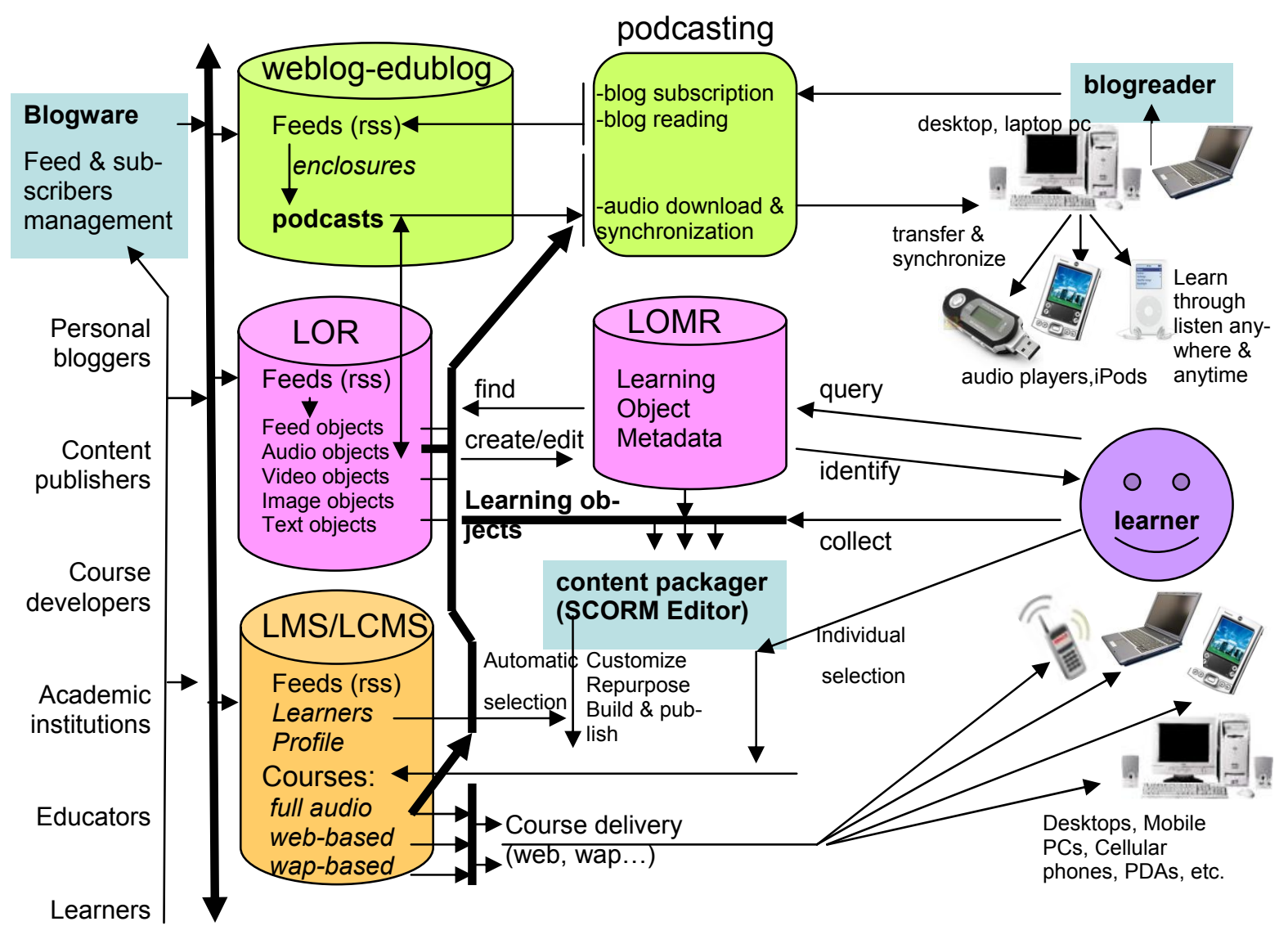

Figure 1: System architecture for publishing and customizing learning objects as podcasts

As argued by Wagner (2002), learning objects appear to have significant potentials for creating highly personalized learning programs, easily updated courses, and performance support tools. He also proposed that learning designers must think about better ways to conceptualize and create resources and programs. Due to availability in number and diversity of audio object offered in the Web, podcasting allows to take advantages of customization, or the ability to personalize the content as close to learner preferences as possible. As described by Downes (2004, par. 14) "personalization is often depicted in terms of content selection of particular materials will be based on individual needs." We generally apply this personalization as a three-fold process according to learner's goals and preferences:

1. Finding the appropriate learning objects that suits learner needs

2. Collecting and aggregating learning objects to form a course package for each learner

3. Publishing the individual course package to specific learner

As described above, personalization is, however, generally understood as individual selection and organization of learning materials. It can occur at three different levels of the instructional process as listed below:

1. Look and feel at the learning object level,

2. Organization of learning materials,

3. Learning content level (Sun, Williams, Ousmanou, \& Lubega,, 2003). 
First level of personalization aims to form and shape the learning object itself. For an audio learning object, it covers the structural elements and principles on the choice of content speech, duration and recording techniques including sound format and quality. In fact, this topic includes creating and formatting techniques for different level of education. For audio learning objects it is typically similar to WALO design described above.

Personalization at the level of organization of learning materials can be done in four ways:

- The learner himself/herself searches LORs and/or the Web to find and collect appropriate learning objects based on LOM, and then individually builds his/her own course package with a packaging tool like a SCORM editor.

- The educator knows the profiles of learners and he/she builds suitable content packages for each learner.

- The learner and the educator together select the materials that suit the learner's needs. This is a combined or blended customization process which may be a more effective way to reach learning objectives.

- A LMS/LCMS has a profile management component that knows the registered learners, and its built-in SCORM engine automatically creates and delivers specific course content for each learner.

A third level of personalization can occur at the learning content. This level of personalization is more difficult than the others because it requires knowing the learning style and learning level of each learner. The educational difficulty level of the content is another important criterion in this type of personalization. In addition, monitoring or tracking the learners is also recommended to determine each learner's achievement and difficulties confronted in learning process. All feedback information in a learning process should be used by educators to refine or to reorganize personalized learning packages. Since this might be a time-consuming and costly process, intelligent agents may be used as an integral part of an LMS/LCMS. These agents should automatically record and analyze the learning performance as well as the troubles encountered by each learner. They must also report feedbacks to the instructors. When the success and failure reports are generated by automatic engines, the individual feedbacks are sent by the learners via a messaging system. The instructor can then easily see the weak and powerful points in learning package. The results can allow for rebuilding the content.

In order to accomplish the above, tools and methods must be developed and applied in LMS/LCMS architectures. A "method for personalized instructional design (MPID)" developed by Sun et al. (2003), can be used as a good starting point in developing approaches, techniques and tools in this context. As an example of personalization in LMS/LCMS, MPID aims to "build a software component through which the individual learners can express their learning requirements, e.g., a way they prefer a presentation for the learning materials, a selection of the learning contents, and sequencing of the learning objects." (p. 1).

\section{Conclusions}

Podcasting is an opportunity to extend and improve lectures beyond classrooms, especially for courses such as music, theatre, language, etc. Downes (2004, par. 14) argues that "the use of syndication technologies (and specifically XML) allows the same content to be presented in plain text, large print, or audio". This means that audio learning objects provide invaluable options to personalize the needs for the auditory learners who prefer learning through listening. According to Sun et al. (2003, p. 4) "auditory learners learn best through verbal lectures, discussions, talking things through and listening to what others have to say and often benefit from reading text aloud 
and using a tape recorder. For these learners, written information may have a little meaning until it is heard".

Podcasting has a great potential for a more humanistic or social learning environment. Washabaug $(2003$, par. 5, 6) argues that "A variety of learning objects have been developed to foster knowledge, but rather few to develop understanding. Such learning objects will help students to discern the components of social life and to recognize the implications of connected conditions and conjoined forces". If podcasts are served via LMS/LCMS as learning objects, they can match the desired learning objective to develop understanding.

At present, few universities have started to experience podcasting in education. In scope of the "Academic iPod Project", Duke University in the USA, in collaboration with Apple Computer, Inc., distributed free-of-charge iPods with $20 \mathrm{~GB}$ hard drive to the first year classes of their university degree programs in 2004. They also started to publish the audio courses on music, language, economics, history and theology (Belanger, 2005). Again in the USA, School of Education at Drexel University realized a smaller iPod Project compared to Duke's Project in 2005. Drexel considers that their students will create and utilize the podcasting materials, and discover their advantages as learning and teaching medium (Read, 2005). In the Drexel's Project, 30 GB iPod Photo devices have been distributed to the first year students free of charge.

Podcasting is a newly applied Web syndication and it is being adopted as potential learning objects in e-learning environments. According to the query results in April 2005 from Web search engines Altavista and Google, podcasting portals and educational blogs (i.e., Edu_RSS, Sieblogs, EBN and ElearnSpace); there are a limited number of content developers who pay special attention in development of audio learning objects that are compatible to learning standards. But, in the near future they will inevitably concentrate on this area when the economic potential of podcasting for e-learning is discovered more clearly.

As argued by Rogers and Scott (1997), the characteristics of an innovation perceived by members of a social system impact the rate of adoption. Characteristics such as relative advantage, compatibility, trialability and observability increase the adoption rate of an innovation whereas complexity reduces the rate of adoption. For example, podcasting has become popular because of its high compatibility and trialability characteristics. Since it is demanded by a great part of members of the social system, especially by young people, this increases its relative advantages. Therefore, podcasting should be given more attention to utilize its advantages in e-learning, particularly in mobile learning.

Mobile videocasting is another emerging technology that offers opportunities for a large set of applications. Therefore, mobile audio players may eventually replace video players. But mobile video players are still expensive and do not provide unique advantages of audio players such as listening while driving, running, etc.

In the e-learning arena, the concept of the learning object has been discussed intensively for several years. Standards, implementations and applications have been developed. But the content for learning objects is still limited. Because of its relative simplicity, podcasting offers great promise for producing and enriching learning objects. As noted by Ip et al. (2000) it is necessary to recognize the subtle difference between an "educational resource" and the "educational potential of a resource". This means that podcasts should be redesigned with a close convergence of instructional theory and syndication technology. Therefore methods of using podcasting in e-learning should be developed more intensively and their incorporation into existing learning systems must be given careful attention. 


\section{References}

Belanger, Y. (2005). Duke University iPod first year experience final evaluation report. Retrieved January, 2006, from http://cit.duke.edu/pdf/ipod_initiative_04_05.pdf.

Berk, A., \& Cebeci, Z. (2005). E-learning perceptions of undergraduate students at the Faculty of Agriculture, Çukurova University. (uncompleted survey study).

Downes, S. (2002). An introduction to RSS for educational designers. Retrieved April 12, 2005, from http://www.downes.ca/files/RSS_Educ.htm

Downes, S. (2003). RDF site summary 1.0 modules: Learning object metadata. Retrieved May 10, 2005, from http://www.downes.ca/xml/rss lom.htm

Downes, S. (2004). From classrooms to learning environments: A midrange projection of e-learning technologies. College Quarterly, 7(3). Retrieved April 22, 2005, from

http://www.collegequarterly.ca/2004-vol07-num03-summer/downes.html

Ip, A., Morrison, I., Currie, M. \& Mason, J. (2000). Managing online resources for teaching and learning. Proceedings Of AusWeb2K, the Sixth Australian World Wide Web Conference, Rihga Colonial Club Resort, Cairns, 12-17 June 2000. Retrieved April 14, 2005, from http://ausweb.scu.edu.au/aw2k/papers/ip/index.html

Keller, J. M. (1999). Applying the ARCS model of motivational design in distance learning. Retrieved May 2, 2005, from http://mailer.fsu.edu/ jkeller/john

Harman, K. \& Koohang, A. (2005). Discussion board: A learning object. Interdisciplinary Journal of Knowledge and Learning Objects, 1, 67-77. Available at http://ijklo.org/Volume1/v1p067077Harman.pdf

Levine, A., Lamb, B. \& Norman D. (2003). Syndicating learning objects with RSS and Trackback. MERLOT International Conference, August 8, 2003. Retrieved May 2, 2005, from http://www.mcli.dist.maricopa.edu/show/merlot03/merlot lo rss_paper.pdf

Lomas, C. (2003). Storing learning objects in our weblogs? Retrieved May 10, 2005, from http:/www.sitegeist.com/stories/2003/10/04/storingLearningObjectsInOurWeblogs.html

Long P. D. (2003). Learning object in motion. Syllabus, April 2003. Retrieved May 2, 2005, from http://www.campus-technology.com/article.asp?id=7479

Manning, S. (2005). The promise of Podcasting. Pointers \& Clickers, 6(2). Retrieved May 2, 2005, from http://www.ion.illinois.edu/resources/pointersclickers/2005 03/Podcasting2005.pdf

Martinez, M. (2002). Adaptive and personalized learning: Supporting individual learning differences. Retrieved April 14, 2005, from http://www.trainingplace.com/source/research/masspersonalization.htm

Meng, P. (2005). Podcasting \& vodcasting: Definitions, discussions \& implications. A White paper by IAT Services at University of Missouri. Retrieved May 12, 2005, from http://edmarketing.apple.com/adcinstitute/wp-content/Missouri_Podcasting_White Paper.pdf

Norman, D., 2004. Podcasting for education. Retrieved April 12, 2005, from http://www.darcynorman.net/2004/10/30/podcasting-for-education.

Read, B. (2005). Seriously, iPods are educational. The Chronicle of Higher Education, Section: Information Technology, 51(28), A30. Retrieved May 2, 2005, from http://chronicle.com/free/v51/i28/28a03001.htm

Rogers, E. M. \& Scott, K. L. (1997). The diffusion of innovations model and outreach from the National Network of Libraries of Medicine to Native American communities (Draft paper prepared for the $\mathrm{Na}$ tional Network of Libraries of Medicine, Pacific Northwest Region, Seattle). Retrieved May 2, 2005, from http://nnlm.gov/pnr/eval/rogers.html

Sun L., Williams, S., Ousmanou, K. \& Lubega, J. (2003). Building personalized functions into dynamic content packaging to support individual learners. Proceedings of the 2nd European Conference on e- 
Learning, Glasgow, pp. 439-448. Retrieved April 12, 2005, from

http://www.ais.reading.ac.uk/papers/con41-building\%20personalised.pdf

Wagner, D. D. (2002, June 18).The new frontier of learning object design. The eLearning Developers Journal. Retrieved April 14, 2005, from http://www.elearningguild.com/pdf/2/061802dst-h.pdf

Washabaugh, W. (2003). Learning objects in a constructivist curriculum. Teaching with Technology Today 9(6). Retrieved May 2, 2005, from http://www.uwsa.edu/ttt/articles/washabaugh.htm

Wikipedia (2005) Podcast definition (last modified 02:21, 13 Apr 2005). Retrieved April 19, 2005, from http://en.wikipedia.org/wiki/Podcast

Wiley, D. A. (2000a). Connecting learning objects to instructional design theory: A definition, a metaphor, and a taxonomy. In D.A. Wiley (Ed.), The instructional use of learning objects: Online version. Retrieved April 2, 2005, from: http://reusability.org/read/chapters/wiley.doc.

Wiley, D. A. (2000b). Learning object design and sequencing theory. Unpublished Ph.D. Thesis, Brigham Young University. Retrieved May 2, 2005, from

http://davidwiley.com/papers/dissertation/dissertation.pdf

\section{Biographies}

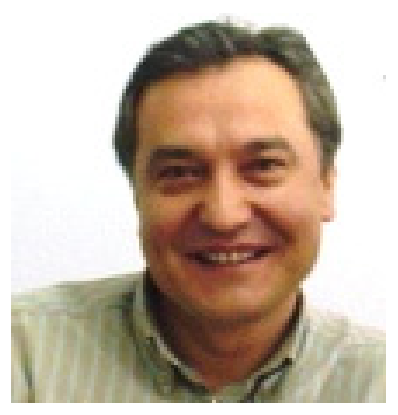

Zeynel Cebeci, Ph.D. is a faculty member in the Division of Biometry and Genetics in the Faculty of Agriculture at the Cukurova University in Adana, Turkey. In addition, he has been the director of the Computer Sciences Rsrch. \& Appl. Center at the Cukurova University from 2000 to 2004. He teaches courses on biometrical methods and information/communication technologies. His research interests include programming languages, software development, computational biology, biometrical methods and algorithms. He also conducts the research and implementation works on e-learning systems and technology.

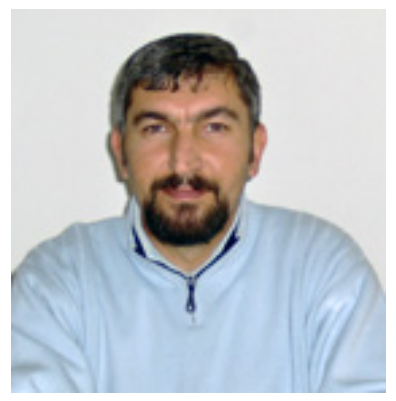

Mehmet Tekdal, Ph.D. is head of the Department of Computer \& Instructional Technologies Education in Faculty of Education at the University of Cukurova in Adana, Turkey. He currently teaches courses on programming languages, operating systems, computer-based physics, and authoring tools. His current research interests include e-learning, learning objects, multimedia-based instructional design, and simulations. 